\title{
Bringt zusammen, was zusammen gehört: die Stellenbörse der DRG
}

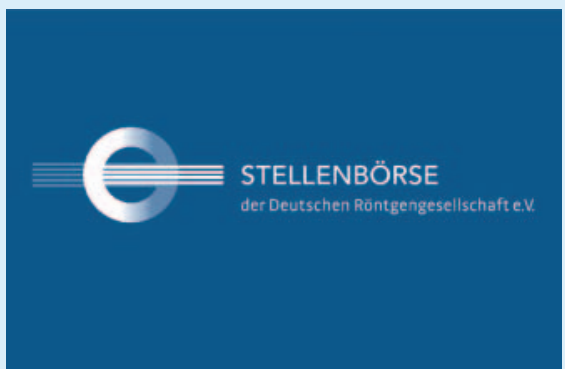

Sie suchen Fachpersonal - oder sind selbst auf der Suche nach einer neuen beruflichen Herausforderung? Die Lösung für beides: die Stellenbörse für Radiologie, Nuklearmedizin, Strahlentherapie, Strahlenbiologie, -physik und -technik. Nutzen Sie die Stellenbörse der Deutschen Röntgengesellschaft für die optimale Zielgruppenansprache!

\section{Stellenausschreibungen}

In der Stellenbörse der DRG finden Sie aktuelle Stellenangebote aus dem Bereich der Radiologie. Wenn Sie eine Anzeige veröffentlichen möchten, nutzen Sie bitte das entsprechende Online-Formular (drg.de > Über uns > Stellenbörse > Schreiben Sie eine Stelle aus)

Wählen Sie aus unserem Angebot:

\begin{tabular}{|l|l|}
\hline Laufzeit & Preis \\
\hline 3 Monate & $350,00 €$ \\
\hline 6 Monate & $500,00 €$ \\
\hline 12 Monate & $800,00 €$ \\
\hline
\end{tabular}

Alle Preise verstehen sich zuzüglich 19\% MwSt.

\section{Bei Fragen steht Ihnen Frau Strauß} gerne zur Verfügung:

E-Mail: strauss@drg.de

Tel.: 030-916 07033

Alle weiteren Informationen finden Sie auf drg.de > Wir über uns > Stellenbörse 